\title{
Cognitive and Motivational Monitoring during Enriched Sport Activities in a Sample of Children Living in Europe. The Esa Program
}

\author{
Marianna Alesi ${ }^{1, *}$, Carlos Silva ${ }^{2}$ (D), Carla Borrego ${ }^{2}$, Diogo Monteiro ${ }^{2}$ (D), Rosario Genchi ${ }^{3}$, \\ Valentina Polizzi ${ }^{3}$, Musa Kirkar ${ }^{3}$, Yolanda Demetriou ${ }^{4}$, Judith Brame ${ }^{4}$, Fatma Neşe Şahin ${ }^{5}$, \\ Meltem Kızılyallı ${ }^{5}$, Manuel Gómez-López ${ }^{6}$, Guillermo López Sánchez ${ }^{6}$ (D), Simona Pajaujiene ${ }^{7}$, \\ Vinga Indriuniene ${ }^{8}$, Ante Rađa ${ }^{9}$ (iD) and Antonino Bianco ${ }^{1}$ (i) \\ 1 Department of Psychological, Pedagogical and Educational Sciences, University of Palermo, \\ Viale delle Scienze, Ed. 15, 90128 Palermo, Italy; antonino.bianco@unipa.it \\ 2 Escola Superior de Desporto de Rio Maior (IPSantarém), Av. Dr. Mário Soares, 20413 RIO Maior, Portugal; \\ csilva@esdrm.ipsantarem.pt (C.S.); ccborrego@esdrm.ipsantarem.pt (C.B.); \\ diogomonteiro@esdrm.ipsantarem.pt (D.M.) \\ 3 University of Palermo Sport Center (CUS Palermo), Via Altofonte, 80, 90129 Palermo, Italy; \\ rosgenchi@gmail.com (R.G.); polizzivalentina26@gmail.com (V.P.); kirkar@ceipes.org (M.K.) \\ 4 Department of School of Sport and Health Sciences, Technical University of Munich, Uptown Munich \\ Campus D, Georg-Brauchle-Ring 60/62, 80992 Munich, Germany; yolanda.demetriou@tum.de (Y.D.); \\ judith.brame@tum.de (J.B.) \\ 5 Department of Sport and Health, Faculty of Sport Sciences, Ankara University, Golbaşı Yerleşkesi Spor \\ Bilimleri Fakültesi, Golbaşı, 06830 Ankara, Turkey; nesehome@hotmail.com (F.N.S.); \\ meltemkizilyalli@ankara.edu.tr (M.K.) \\ 6 Department of Physical Activity and Sport, Faculty of Sports Sciences, University of Murcia, \\ Calle Argentina, s/n., 30720 Murcia, Spain; mgomezlop@um.es (M.G.-L.); gfls@um.es (G.L.S.) \\ 7 Department of Coaching Science, Lithuanian Sports University, Sporto 6, LT-44221 Kaunas, Lithuania; \\ Simona.Pajaujiene@1su.lt \\ 8 Department of Health, Physical and Social Education Department, Lithuanian Sports University, Sporto 6, \\ LT-44221 Kaunas, Lithuania vinga.indriuniene@1su.lt \\ 9 Faculty of Kinesiology, University of Split, Teslina 6, 21000 Split, Croatia; arada@kifst.hr \\ * Correspondence: marianna.alesi@unipa.it; Tel.: +39-091-23899702
}

Received: 20 November 2017; Accepted: 8 December 2017; Published: 13 December 2017

Enriched Sport Activities (ESA) Program is an Evidence-based Practice Exercise Program cofounded by the Erasmus + Programme of the European Union (Key action: Sport-579661-EPP-1-2016-2-IT-SPO-SCP). It aims to enhance social inclusion, equal opportunities and psycho-physical wellbeing in children with typical development and special needs. This aim will be pursued through two ways: (1) Children and preadolescents' participation in Enriched Sport Activities (ESA) Program; (2) Parents' involvement and education on cognitive, motivational and social benefits of Physical Activities (PA) in their children.

Recent research showed that high-level cognitive processes, such as inhibition, shifting, working memory and planning, can be improved by aerobic exercise programs following both single bouts of exercise and longer trainings from moderate to vigorous intensity [1]. Nevertheless, in the developmental age, structured sport activities, such as martial arts, basketball, soccer, rowing and dancing, act by delivering both physical and psychological benefits. The former involve physical fitness such as cardiorespiratory fitness, muscular strength, muscular endurance, flexibility and motor skills such as coordination, whilst the latter concern enjoyment, self-confidence and self-esteem, a sense of belonging and social support [2-4]. The effectiveness of PMA (Programma Motorio Arricchito), a structured motor program on coordination and executive functioning in kindergarten children, has been demonstrated [5]. Moreover, exercise intervention trainings directed at increasing motor 
abilities in individuals with intellectual disabilities revealed to be efficacious to increase specific cognitive abilities such as reaction times [6,7].

Nevertheless, family stimulates children's participation in Physical Activity (PA) because of its key role to influence the choice of social and physical activities in childhood. Specifically, family influences the amount, the duration and the complexity of sport activities both in typically and atypically developing children by providing adequate scaffolding during collaborative performances as well as stimulating the sense of competence and the mastery motivation needed to cope challenging physical tasks [8,9].

On the basis of these theoretical premises, the ESA project aims at enhancing social inclusion, equal opportunities and psycho-physical wellbeing in children with typical development and special needs. It will be developed over three years and it involves a specialized practitioners team (coaches, sport scientists and psychologists) and the establishment of a European network among families, practitioners and schools. The intervention is carried out in seven European countries: Italy, Germany, Portugal, Spain, Lithuania, Croatia and Turkey.

According to the ESA Program aims, the TEG (Technical Expert Group) in charge with the Thematic Area 2 (TA2-cognitive functioning, sport motivation, social inclusion, equal opportunities and special needs) is focusing on a systematic literature review to provide the current evidence on the effects of PA programmes on enhancing children's and adolescents' motivation towards physical activity. Additionally, SOPs (Standard Operating Procedures) have been defined to select tests able to predict and monitor cognitive, social and motivational growth in a population target of children (6-14 years) living across Europe. The age range from 6-14 years was chosen because children's PA levels are acknowledged to decrease over this stage, with higher rates of drop-out in girls' population, but also because this is a critical phase to address precautionary intervention programs aimed at stimulating an active lifestyle able to prevent inactivity.

Starting from previous successful experiences, the TEG has implemented: (1) the Enriched Sport Activities (ESA) Program by adapting and enlarging previous successful experiences such as PMA and exercise intervention trainings [5]; (2) a Parent Education Program to train parents on cognitive, motivational and social benefits deriving from regular PA in childhood and establish educational models and strategies to improve participation in PA by their children. ESA is an integrated sport program in which 27 sessions of warm up in sport activities for typical children, such as soccer, track and field, swimming, basketball, handball and APA (Adapted Physical Activities) for children with special needs are enriched by cognitive tasks aimed at improving executive functions as working memory, shifting and inhibition processes. The Parent Education Program is composed of four sessions that will be carried out for each group of parents (10-12 max group members).

The aim is to provide, encourage and improve parents' strategies aimed at supporting motivation towards PA in their children. During "ESA Parent Education Program" the parents will be involved in group discussions about how to provide their children a climate characterized by high levels of support and patience, not to judge negative manifestations or the expression of negative affect concerning their children's sport performances, to encourage children to choose what they are more interested in and to choose what kind of sport activity is the best for their psycho-physic wellness.

Next step is the administration of the ESA Program and the Parent Education. To sum up, ESA Program aims at implementing guidelines to enhance cognitive abilities, motivation and participation in sport activities as natural and enjoyable instruments of growth. The final goal is to stimulate global development in children with typical development and special needs [10]. However, the main limitation of the program study is the future generalizability of the findings regarding the population with special needs because only two groups with special needs (children with Asthma and children with Down Syndrome) participate in the project. So, in the future the sample with special needs need to be enlarged.

Future contributions to the field are to establish a network approach involving educational agencies as families, practitioners and schools. This network approach has been chosen because 
traditional physical activity promotion interventions using individual approaches have revealed to be limited in long-term maintenance of benefits. After the project lifetime the web platform (ESA database, ESA cloud, ESA tasks, ESA smartphone apps, ESA school programs) will be available to be adopted for further European Union projects and initiative. In more details, every European citizen can easily visit the ESA Program web site and can discover the ESA aims, ESA research units, current researchers, reports, statistics and most important normative values and guidelines for best practices.

Conflicts of Interest: The authors declare no conflict of interest.

\section{References}

1. Davis, C.L.; Tomporowski, P.D.; McDowell, J.E.; Austin, B.P.; Miller, P.H.; Yanasak, N.E.; Allison, J.D.; Naglieri, J.A. Exercise Improves Executive Function and Achievement and Alters Brain Activation in Overweight Children: A Randomized Controlled Trial. Health Psychol. 2011, 30, 91-98. [CrossRef] [PubMed]

2. Haapala, E.A. Cardiorespiratory Fitness and Motor Skills in Relation to Cognition and Academic Performance in Children-A Review. J. Hum. Kinet. 2013, 36, 55-68. [CrossRef] [PubMed]

3. Diamond, A. Effects of Physical Exercise on Executive Functions: Going beyond Simply Moving to Moving with Thought. Ann. Sports Med. Res. 2015, 2, 1011. [PubMed]

4. Alesi, M.; Bianco, A.; Padulo, J.; Luppina, G.; Petrucci, M.; Paoli, A.; Palma, A.; Pepi, A. Motor and cognitive growth following a Football Training Program. Front. Psychol. 2015, 6, 162. [CrossRef] [PubMed]

5. Alesi, M.; Galassi, C.; Pepi, A. Programma Motorio Arricchito. Educare allo Sviluppo Motorio e allo Sviluppo delle Funzioni Esecutive in età Prescolare, 1th ed.; Edizioni Junior, Gruppo Spaggiari: Parma, Italy, 2016; ISBN 978-88-8434-778-7.

6. Alesi, M.; Battaglia, G.; Roccella, M.; Testa, D.; Palma, A.; Pepi, A. Improvement of gross motor and cognitive abilities by an exercise training program: Three case reports. Neuropsychiatr. Dis. Treat. 2014, 10, 479-485. [CrossRef] [PubMed]

7. Sundahl, L.; Zetterberg, M.; Wester, A.; Rehn, B.; Blomqvist, S. Physical Activity Levels among Adolescent and Young Adult Women and Men with and without Intellectual Disability. J. Appl. Res. Intellect. Disabil. 2016, 29, 93-98. [CrossRef] [PubMed]

8. Batey, C.A.; Missiuna, B.W.; Timmons, J.A.; Hay, B.E.; Faught, J.; Cairney, M. Self-efficacy toward physical activity and the physical activity behavior of children with and without Developmental Coordination Disorder. Hum. Mov. Sci. 2013, 36, 258-271. [CrossRef] [PubMed]

9. Alesi, M.; Pepi, A. Physical Activity Engagement in Young People with Down Syndrome: Investigating Parental Beliefs. J. Appl. Res. Intellect. Disabil. 2017, 30, 71-83. [CrossRef] [PubMed]

10. EU Commission: Special Eurobarometer 412. Sport and Physical Activity; Social, SEWETO, Ed.; EU Commission: Brussels, Belgium, 2014.

(C) 2017 by the authors. Licensee MDPI, Basel, Switzerland. This article is an open access article distributed under the terms and conditions of the Creative Commons Attribution (CC BY) license (http://creativecommons.org/licenses/by/4.0/). 